\title{
Development of a fast-hardening retarding high-early-strength concrete with low- alkalinity sulphoaluminate cement and practical application
}

\author{
Zhijun Sha' ${ }^{1}$ Xiang Long ${ }^{2}$, Jiahui Feng ${ }^{1}$, Haibo Jiang ${ }^{1 *}$ (D) and Tianlong Wang ${ }^{3}$
}

* Correspondence: hbjiang@gdut. edu.cn

${ }^{1}$ School of Civil and Transportation Engineering, Guangdong University of Technology, Guangzhou 510006, China

Full list of author information is available at the end of the article

\section{Abstract}

To widen bridges, a usual method is to cast joint connections between new and old bridge decks without traffic interruption. The traffic vibrations have negative influence on the quality of joint connections. Shortening the construction time can alleviate the impact on the traffics, a fast-hardening retarding high-early-strength concrete (FRHC) for the connections is in need. In this study, low-alkalinity sulphoaluminate cement (LASC) concrete was modified to gain these characteristics. Based on FRHC concrete, four slab specimens including a monolithic concrete slab and three joint FRHC slabs were cast to investigate their flexural behaviors. With proper splicing details in joint connections, the joint FRHC specimens behaved approximately similar to the monolithic specimen. Combing the laboratory tests and engineering practice, the newly developed FRHC mixture succeeded in fasthardening, retarding and high-early strength and the joint connections filled with FRHC have a good flexural performance.

Keywords: Low-alkalinity sulphoaluminate cement concrete, Fast-hardening retarding high-early-strength concrete (FRHC), Setting time, Concrete mixture, Joint connections

\section{Introduction}

Guanghe expressway was built in 2012, linking Guangzhou city and Heyuan city in Guangdong Province, China. Nowadays, the west extension of Guanghui expressway was under construction and about to link to Guanghe expressway at Chungang bridge. It was predicted that the traffic volume was going to grow heavily, the existing Chungang bridge wolud be finally unable to meet the increasing demand and become congested, especially in rushing hours. In such a situation, bridge widening was recommended. A usual method of widening the bridge is to construct a new deck by the side of the existing one with a joint connection filled by cast-in-place concrete, shown in Fig. 1.

(c) The Author(s). 2020 Open Access This article is licensed under a Creative Commons Attribution 4.0 International License, which permits use, sharing, adaptation, distribution and reproduction in any medium or format, as long as you give appropriate credit to the original author(s) and the source, provide a link to the Creative Commons licence, and indicate if changes were made. The images or other third party material in this article are included in the article's Creative Commons licence, unless indicated otherwise in a credit line to the material. If material is not included in the article's Creative Commons licence and your intended use is not permitted by statutory regulation or exceeds the permitted use, you will need to obtain permission directly from the copyright holder. To view a copy of this licence, visit http://creativecommons.org/licenses/by/4.0/. 


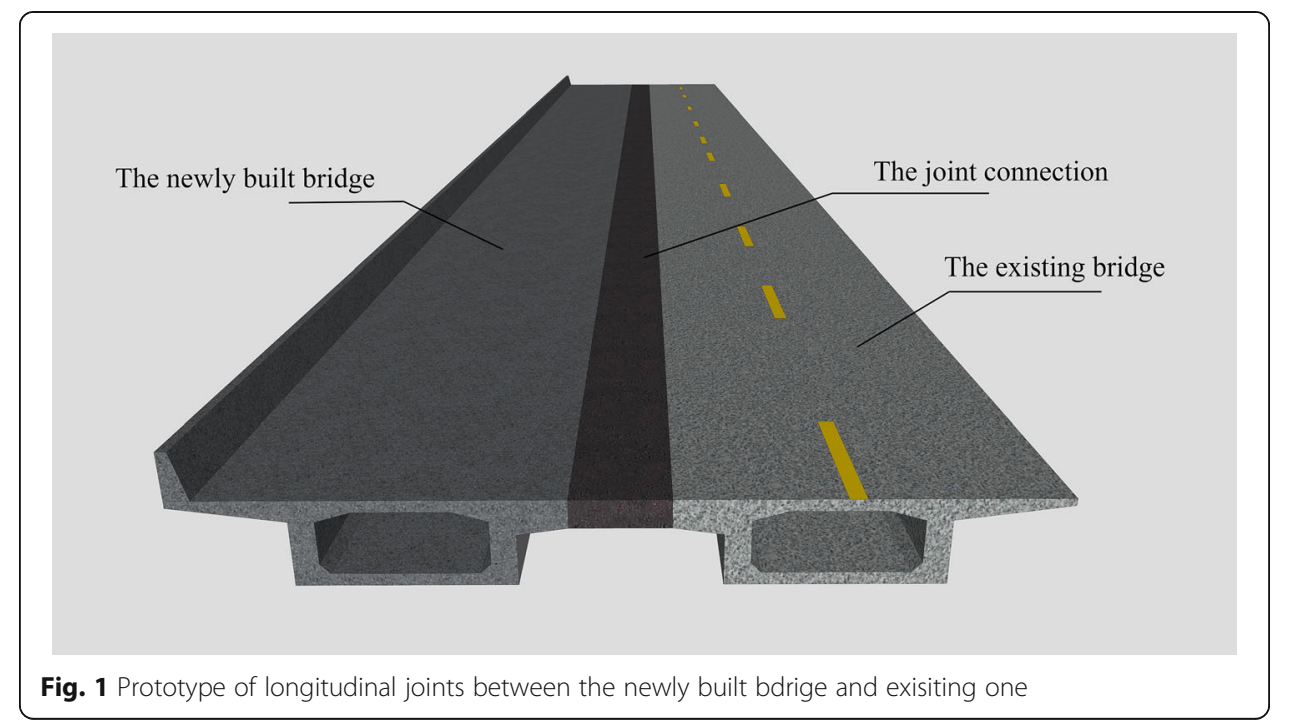

In practice, the existing slabs are required to maintain traffics and subject to the traffic vibrations during the joints construction. However, the negative influence of traffic vibrations on the joint connections has been confirmed by some researches. Before the initial set, continuous traffic vibrations will cause some extent of bleeding to cement mortar or concrete mixtures (Zhang et al. 2019). If the traffic vibrations occur during the setting period, it will probably damage or obstruct the connection of the solid skeleton (Chen et al. 2009) in the PVA-ECC. The traffic vibrations will accelerate the transportation of free water toward the anhydrous cement particles which would increase the degree of hydration, affecting the flexural properties of joint connections as a consequence. To alleviate the impact of the traffic vibrations, the joint connections are usually completed at night or during periods of low traffic volumes. In the majority of situations, the scenario for widening projects provides a window of about $8 \mathrm{~h}$ of total construction time for the joint connections. This time includes new concrete placement, finishing, and required strength development. Due to the short time available for the widening operations, it is very important to minimize the time required for concrete placement and strength development. Therefore, FRHC is in need.

LASC produced by adding gypsum and limestone into the sulphoaluminate cement clinker has many superior characteristics, such as high early strength, fast setting, low alkalinity, high frost and permeation resistance. Therefore, LASC obtains increasing attention (Juenger et al. 2011; Gartner 2004; Popescu et al. 2003). Due to the characteristic of fast hardening and high early strength, LASC is selected to develop the FRHC to apply in the widening bridge projects (Ye et al. 2010; Gastaldini et al. 2010; Glasser and Zhang 2001). Compared to the ordinary Portland concrete (OPC), LASC is regarded as environmental-friendly cementitious materials because during the process of manufacturing LASC produces lower CO2 emissions (Juenger et al. 2011), and has lower energy requirement. Moreover, LASC can be manufactured by using many industrial byproduct such as fly ash, blast furnace slag, phosphogypsum and scrubber sludge (Gartner 2004; Popescu et al. 2003). However, LASC has too short setting time and the LASC concrete always sets at $30 \sim 40 \mathrm{~min}$, which is not appropriate to concrete construction procedure. The concrete used for filling joint connection should set during $90 \sim 120$ 
min, because the long enough setting time can help to keep the plasticity of fresh concrete, so as to facilitate the pouring, improve construction efficiency and ensure the construction quality. The flowing property and setting time of LASC must be modified to success the characteristic of retarding, or will seriously hinder the popularization and application of the LASC.

\subsection{Literature review}

The Sulphoaluminate cement (SAC) has been used in China for over 40 years (Juenger et al. 2011). Nowadays, it is receiving increasing attention due to its lower CO2 emissions than the ordinary Portland cement (OPC) and its characteristics of fast setting and high early strength.

With the improved requirements in engineering cases, there are higher demands in early strength of SAC. In general, SAC's early strength is always focused at the $12 \sim 24$ h. However, to meet the accelerated construction's needs, the 6-h strength was put forward. The fast-hardening sulphoaluminate cement (FHSC) is the kind of cement that the concrete with can succeed the target strength within 6 hours (Guo et al. 2018; Kwon et al. 2018). To prepare FHSC, it was reported that the early strength agent has little influence on improving the strength at 6 hours. For instance, Wang (2018) and Aggoun (2008) added $\mathrm{Na}_{2} \mathrm{SO}_{4}$ and triethanolamine into the SAC respectively, however, the strength was improved at 1 and 3 days respectively, failed to meet the requirements of FHSC. Considering the significant progress in "nano-concrete", and the success application of nano-calcium and nano-silica in reactive powder concrete, Yushi Liu (2020) added nano-material, Graphene oxide, into the SAC. The results showed that, adding Graphene oxide into the SAC could reach the target strength at 6 hour which was $30 \mathrm{MPa}$, while the concrete without Graphene oxide was $20 \mathrm{MPa}$.

Although SAC shows high performance, it is still expensive to produce SAC due to limited raw materials, i.e. aluminum and sulfur sources (Schneider et al. 2011). Adding gupsum and limestone in SAC can decrease the cost, and this new kind cement is known as low alkalinity sulphoaluminate cement (LASC). It is reported that limestone powder can fill in the pores of cementitious materials thus reducing the porosity of cement-based materials (Matschei et al. 2007). It is reported that adding limestone into SAC to prepare LASC can improve the strength (Kenai et al. 2004), permeability (Sakellariou 2003), carbonation resistance and corrosion resistance of reinforced bars (Theodossis 2000; Batis 2002). Hargis (2014) demonstrated that the calcite in LASC with limestone can react with monosulphoaluminate to produce monocarboaluminate and ettringite. Limestone powder can promote early age hear evolution of LASC. The addition of limestone powder can improve the early strength of LASC paste and also improve the strength at later stages (28 days). Ma (2019) explore the effects of limestone powder on the long-term performance of LASC, the hydration process and microstructure development of LASC incorporated with limestone powder are investigated at the ages from 1 day to 1 year.

Fast-hardening retarding high-early-strength concrete (FRHC) is a new kind of concrete, which was designed to meet the needs of accelerated construction and repair construction. To success in high-early-strength, FRHC has the characteristic of fast hardening and high early strength. The concrete with LASC sets within $40 \mathrm{~min}$, which 
is too short to meet the constructions' needs. Therefore, FRHC needs to contain plasticity during the pouring, shipping and placing, which means target setting time is about $90 \sim 120 \mathrm{~min}$.

Many researchers have studied the effect of inorganic admixture on the set retard behavior of the concrete. Shenlai Guo's research indicate that the retarder had better retarding performance with sodium silicate (Guo et al. 2019). Fly ash (FA) has also been used as set retarder in many engineering cases. With high replacement, the FA prolongs the setting time with great retardation (Celik 1995; Naik and Singh 1997; Naik and Ramme 1990). However, at replacement of $70 \%$ or higher, the FA was observed to cause rapid setting (Naik and Singh 1997). As for silica fume (SF), its effect on retarding was also seem to be contradicted. Several researches reported that the SF can prolong the setting time and the retardation increase with replacement level (Khedr and Abou Zeid 1994; Alhosani et al. 1997; Alshamsi et al. 1993), while some researchers claimed that the effect was negligible (Wedding et al. 1984) and the retardation effect was associated with the superplasticizer used in the concrete (Editor 1995). Some researchers also indicated that by suitable calcium sulfate, the calcium sulphoaluminate cement concrete has a good performance of retarding and strength development (Xu et al. 2014; Martin et al. 2015). Borax, at $25^{\circ} \mathrm{C}$, can be precipitated with $\mathrm{Ca} 2+$ of cement grains to adsorb onto the surface of the cement, thereby a calcium-based borate layer is formed, which is responsible for its retarding effect (Ma et al. 2017; Sun et al. 2011; Champenois et al. 2013; Champenois et al. 2015; Zajac et al. 2016). Unfortunately, effects of retarders such as borax on calcium sulphoaluminate cement concrete hydration at high temperature have been not observed.

Superplasricizers (SPs) are indispensable component in the production of concrete and exhibit good dispersing ability for the cement particles. The addition of SPs to concrete can significantly improve the fluidity properties of concrete. Concrete materials of high strength and high durability can be achieved at a low water-binder (W/B) ratio by using SPs (Collepardi and Valente 2006). Nowadays, the conventional SPs used in concrete include modified lignosulphonate (MLS) SP, sulfonated naphthaleneformaldehyde (SNF) SP, sulfonated melamine-formaldehyde (SMF) SP, and sulfonated acetone-formaldehyde (SAF) SP (Sakai et al. 2006). In the 1980s, a new generation of polycarboxylate-based (PCA) polymers was developed as SP in Japan. And the Naphthalane superplasticizer has been widely used in China for its high water-reducing rate, cheap price and stable synthesizing technology. However, there are few researches on comparing the Polycarboxylic SP and naphthalene SP in preparing LASC concrete.

The precast deck systems is more and more applied in engineering cases, so as to accelerate the construction and rehabilitation of bridge deck (Berger 1983). During the construction, the precast decks are lifted and assembled, the predefined gaps between precast decks are left to be cast in place as joint connections. The quality of the joints is essential to the safety of the bridge structures, therefore, many researches have been conducted to study the mechanical properties of the joint connection. The strength and stiffness of the loop-bars joints were investigated by static and fatigue loading (Ryu et al. 2007). The mechanical properties of U-bars and headed bars joints were compared and it was reported that the U-bars 
joint having higher capacity and suitable to accelerated construction (Lewis 2009). Taking contacted lapping U-bar joints as reference, the longitudinal joints reinforced by lapped headed bar and lapped welded wire were investigated, and the lapped headed bar was recommended (Ryu et al. 2007; Li et al. 2010).

\subsection{Research significance}

As mentioned above, FRHC has characteristics of fast hardening, retarding and high early strength. But the research on the FRHC still remains at the preliminary stage. At present, the researchers at home or abroad have mainly succeeded fast-hardening and high-early-strength by adding compound admixture into the ordinary Portland concrete(OPC), while relative research on the concrete with LASC is still in lack. The initial setting and final setting time of the concrete with LASC are vital to its workability and applicability, but there are few researches on it. Also, the researches on the flexural behavior of joint connections filled by FRHC is insufficient.

In this paper, the researchers focused on developing a new kind concrete with characteristics of fast hardening, set retarding, and high early strength, known as FRHC, and the flexural behavior of joint connections filled with it in laboratory. In part I, the effect of admixture types and dosage on the behavior of LASC has been investigated, and the chemical mechanism has been discussed. According to the test results, a new FRHC with LASC has been developed. In part II, based on the test results of part I, a newly developed FRHC was used to fill the joint connections between two precast concrete slabs. A total of four specimen were tested for their flexural behavior.

\section{Research on FRHC}

To meet the needs of the rapid construction without the traffic interruption, a new kind FRHC with LASC was developed. The newly developed concrete achieved of minimizing the impact of the traffic vibrations on constructing longitudinal joint between the existing bridge and the newly built one.

\subsection{Material and parameters}

During the development of the FRHC, the fast-hardening sulphoaluminate cement (FHSC) was introduced to compare with LASC. The effects of several admixtures i.e., borax, aluminum sulfate, superplasticizers (Polycarboxylic superplasticizer and naphthalene superplasticizer) and steel fibers were also investigated. Table 1 exhibits ten concrete mixtures.

To determine the mechanical properties of the concrete, the tests were conducted following the rules listed in the Standard for Test Method of Concrete Physical and Mechanical Properties(GB/T 50081-2019) (2019). For each concrete mixture, three standard cubic specimens were cast and tested for measuring the compressive strength at $6 \mathrm{~h}, 10 \mathrm{~h}, 12 \mathrm{~h}, 1 \mathrm{day}, 3 \mathrm{~d}, 7 \mathrm{~d}$, and $28 \mathrm{~d}$; and three standard cylinder specimens were cast and tested for measuring the splitting strength, Young's modulus and poisson's ratio of $28 \mathrm{~d}$. The test results obtained from the average value of three specimen in each mixture were shown in Table 2. The experiments were carried out during the winter in 


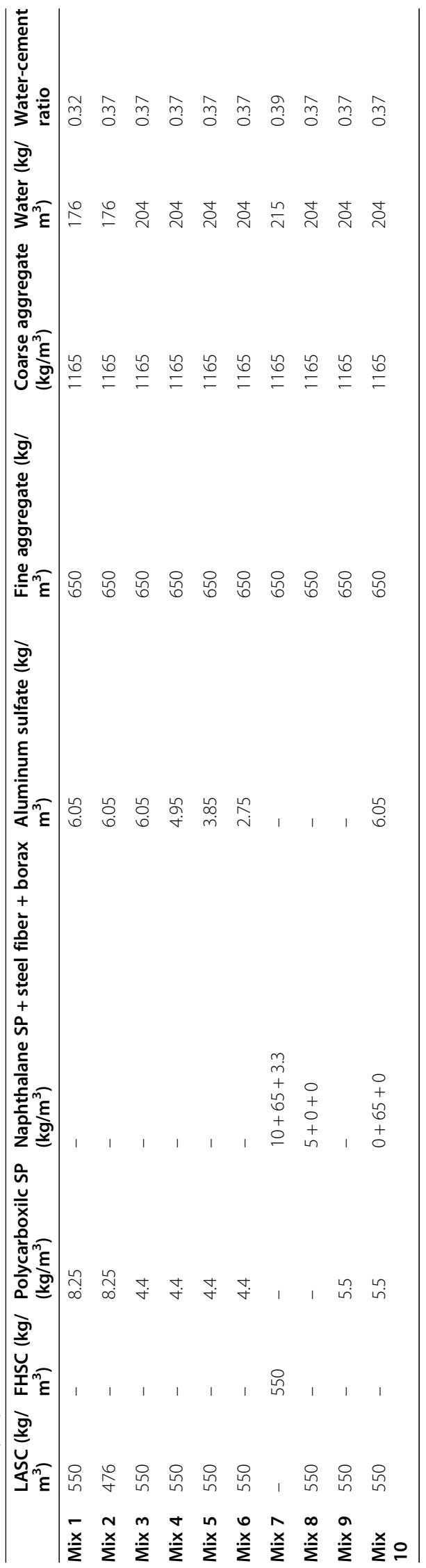




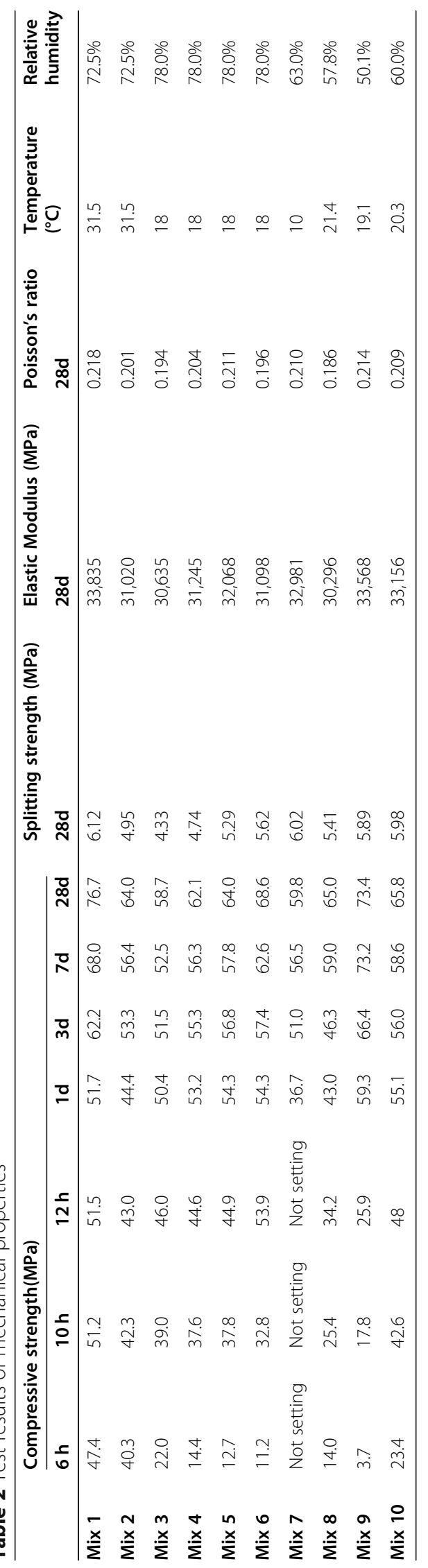


subtropical regions, the temperature and relative humidity were also recorded in Table 2 .

\subsection{Experimental results and discussions}

\subsubsection{Effect of borax}

It is quite a short time for concrete with FHSC concrete to reach its initial setting, resulting in concrete losing plasticity during early period, which is unfavorable for concrete mixing, shipping and casting. It is necessary to extend the setting time. Adding the borax can prolong the initial setting time. From the results of the seventh concrete mixture shown in Table 2, it is noted that the specimens could not set within $12 \mathrm{~h}$. It is because the borax would generate a calcium borate coat covering the surface of the sulphoaluminate cement clinker, thus inhibiting the hydration. The coating thickness of calcium borate varies with the borax content, which is hard to control. The compressive strength reached $36.7 \mathrm{MPa}$ after one-day curing, and was up to $59.8 \mathrm{MPa}$ with 28-day curing. And the splitting tensile strength was $6.02 \mathrm{MPa}$.

Because of the long setting time, more than $12 \mathrm{~h}$ as aforementioned, adding borax to retard set is not applicable for the construction of connecting the existing bridge with the newly built one.

\subsubsection{Effect of aluminum sulfate}

The third to sixth mixtures took into account the effect of aluminum sulfate on mechanical properties, by adjusting the content of aluminum sulfate in the range of $2.75 \sim$ $6.05 \mathrm{~kg} / \mathrm{m} 3$. As illustrated in Fig. 2a, the compressive strength of concrete with LASC increased quickly to about double to five times by $12 \mathrm{~h}$, but the development rate slowed obviously after 1 day. The mixture with $2.75 \mathrm{~kg} / \mathrm{m} 3$ aluminum sulfate experienced about five times compressive strength growth at $12 \mathrm{~h}$, compared with that of $6 \mathrm{~h}$. But as a whole, the concrete with a higher content $(4.95-6.05 \mathrm{~kg} / \mathrm{m} 3)$ of aluminum sulfate performed a higher compressive strength at $6 \mathrm{~h}$. However, after 1 day, it was the concrete with a lower content $(2.75-3.85 \mathrm{~kg} / \mathrm{m} 3)$ of aluminum sulfate that performed a higher compressive strength than that of higher content.

Adding the aluminum sulfate could improve the flowing property of concrete, shorten the induction period of the hydration reaction, and accelerate the hydration, which would enhance the concrete strength at the early age. Higher content of aluminum sulfate could lead to over-rapid hydration reaction, resulting in generating the overlarge ettringite crystals in some area, which fails to evenly distribute in the cement paste, thus inhibiting the strength enhancement. As can be seen from the Table 2 , for mixture 3 to mixture 6 , splitting tensile strength could be enhanced by reducing the content of aluminum sulfate. Also considering the cost of aluminum sulfate, the mixture with lower content was preferred.

\subsubsection{Effect of superplasticizer}

The eighth and ninth mixtures took into account the effect of polycarboxylic SPs and naphthalene SPs on the LASC concrete, and the mixtures details were listed in Table 1. The influence on early strength caused by polycarboxylic SPs and 


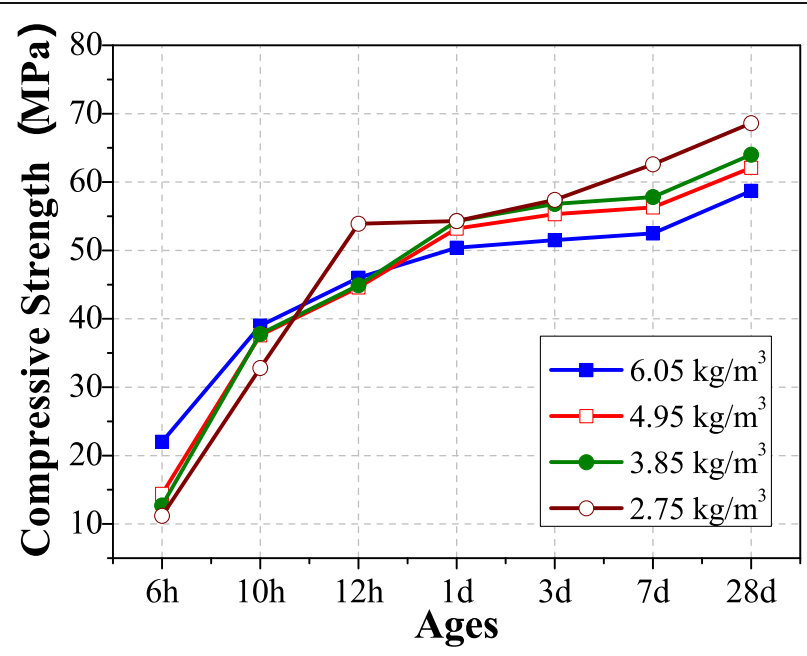

(a)

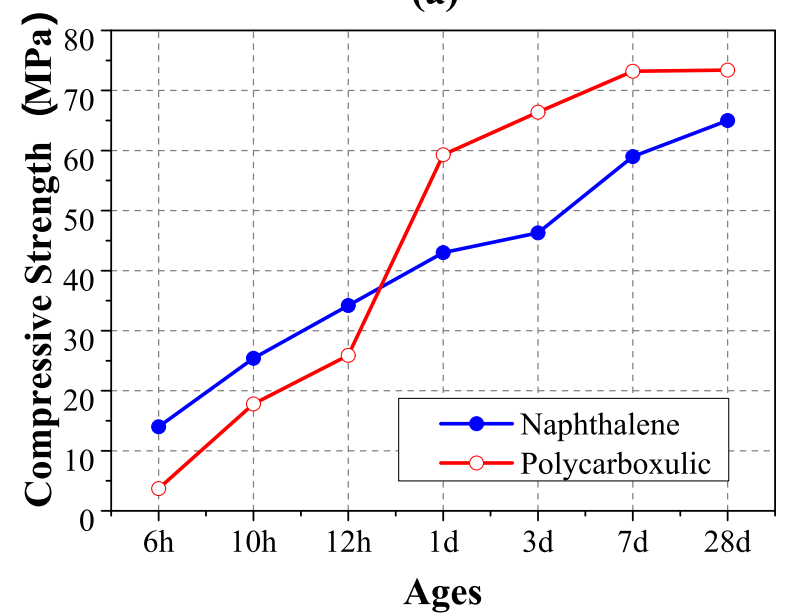

(b)

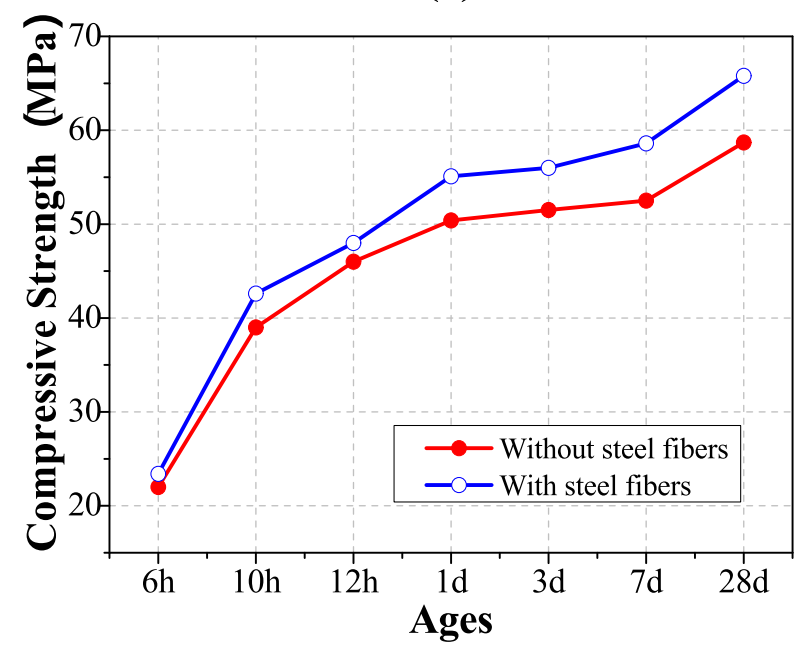

(c)

Fig. 2 Influence factors of compressive strength at different ages. a Aluminum sulfate; b supeprplasticizer; c steel fibers 
naphthalene SPs were compared and analyzed. As shown in Fig. 2b, concrete with polycarboxylic SPs behaved a weaker compressive strength than that of naphthalene SPs during $6 \sim 12 \mathrm{~h}$. Afterwards, compressive strength of concrete with polycarboxulic SPs significantly soared up to $59.3 \mathrm{MPa}$ during $12-24 \mathrm{~h}$ and up to 73.4 $\mathrm{MPa}$ at 28 days, exceeding the value with naphthalene SPs. In terms of the concrete with naphthalene SPs, the compressive strength kept steadily climb.

During the process of LASC's hydration, the molecule of SPs adsorbs on the cement particle surface produce a large electrostatic repulsive force between the cement particles resulting in dispersion ability for the cement particles. The functional groups i.e., $-\mathrm{COOH},-\mathrm{SO} 3$, react with $\mathrm{Ca} 2+$ and generate calcium and enriched the protective layer covering the cement particle, reducing the rate of hydration process. Compared with the concrete with naphthalene SPs, the concrete with polycarboxylic SPs formed a more stable protective coat and reached a slower hydration rate. And the concrete with polycarboxylic SPs has more homogeneous distribution and tiny size of hydration products, resulting dramatically increment of compressive strength. Therefore, the polycarboxylic SPs was recommended.

\subsubsection{Effect of steel fiber}

As cracking is fatal flaw in concrete, which could lead to reduction of the mechanical properties and provide channels for the intrusion of harmful substances in the outside world, it is necessary to restrain concrete cracking and enhance its durability. Utilizing steel fiber is a possible method. The randomly-distributing steel fibers in concrete could inhibit the development of micro cracks in concrete, so as to improve the tensile strength and ductility of concrete.

According to Table 2, the compressive strength of mixture 10 with steel fibers could reach up to $23.4 \mathrm{MPa}$ at $6 \mathrm{~h}$, and $42.6 \mathrm{MPa}$ at $10 \mathrm{~h}$. As shown in Fig. 2c, compared with mixture 3 without steel fibers, the enhancement of compressive strength was not remarkable at the early stage, whereas it became significant after 1 day. In terms of splitting tensile strength, specimens with steel fibers reached an increment of $38.1 \%$, resulting from the bond strength between fibers and the matrix. Because of deforming between fibers and concrete matrix were inconsistent when transferring load, which produced axial shear stress and tensile stress around the fibers. Then, the bond between fibers and the matrix was broken, and the fibers were pulled out at failure. Therefore, using steel fibers to prepare FRHC is recommended.

\section{Research on the flexural behavior of joints connection with FRHC with LASC}

To investigate the flexural behavior of the joint connections of the new and old concrete slabs, four slab specimens consisting of one monolithic slab and three joint slabs were fabricated. The monolithic slab is $1500 \mathrm{~mm}$ in length, $180 \mathrm{~mm}$ in thickness and $500 \mathrm{~mm}$ in width. For each joint slab, it is consisted of two precast slabs and a joint connection. The precast slabs are $500 \mathrm{~mm}$ in length, $180 \mathrm{~mm}$ in thickness and $500 \mathrm{~mm}$ in width. As for the joint connection, its width is $500 \mathrm{~mm}$. The details of the specimens 
(a)
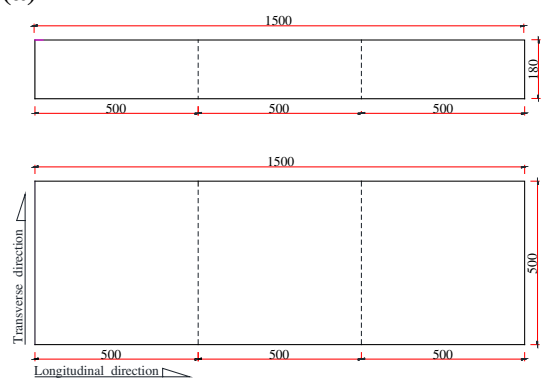

(c)
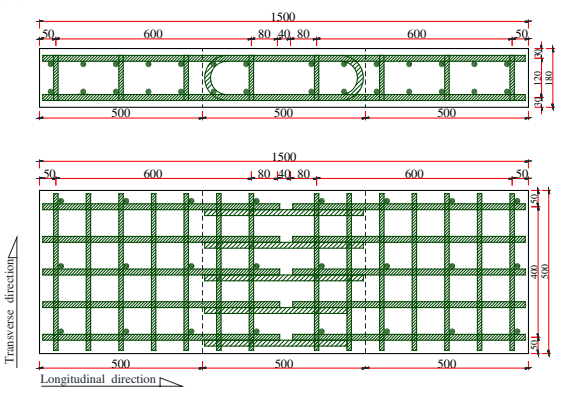

(e)

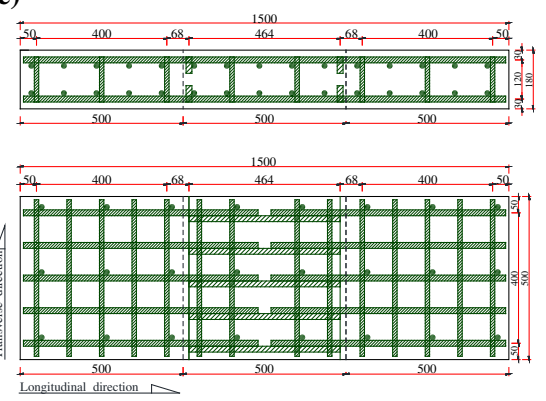

(b)
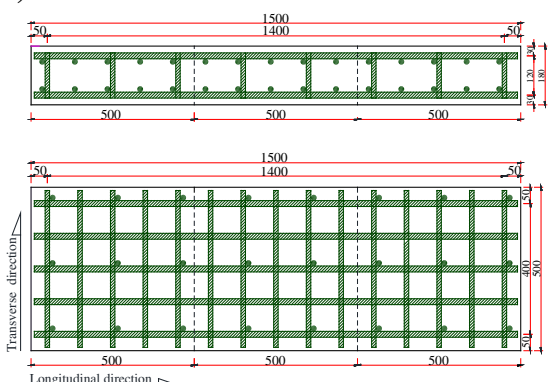

(d)
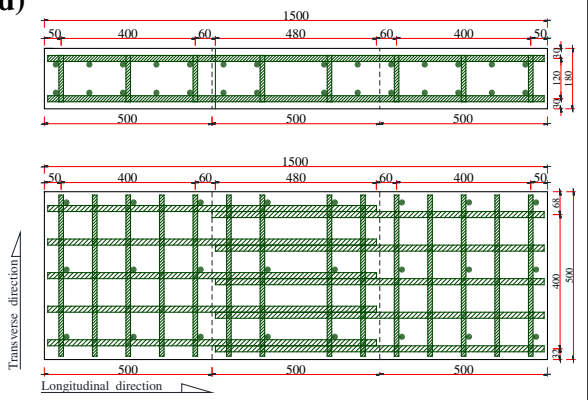

(f)

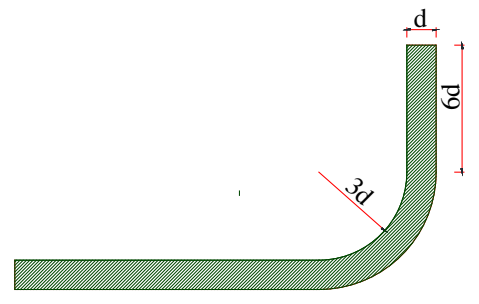

Fig. 3 Specimen dimensions and rebars details (a) specimen direction; (b) M 1; (c) JF 1; (d) JF2; (e) JF 3; (f) standard hook details

were shown in Fig. 3. The parameters of this test were the reinforcement details of the joint zone.

\subsection{Material}

C60 concrete and newly-developed FRHC were applied during the fabrication procedure. C60 concrete, mainly consisted of P.O 52.5 cement, water, fine aggregate and additives was used to cast the precast slab specimens, and the mixtures is shown in Table 3. To select an appropriate concrete mixture to prepare the FRHC, the compressive strength of $6 \mathrm{~h}$ and 28 day and the fluidity was considered. Shown in Fig. 4, it was obvious that the Mixture 1 and Mixture 2 had high strength at 6 hour. However, the FRHC required a high fluidity, and the Mixture 2 had the higher fluidity than Mixture 1 did. Therefore, the new FRHC mixture was based on mixture 2 and used to cast the joint connections between two precast slab 
Table 3 Mix proportion of concrete

\begin{tabular}{|c|c|c|c|c|c|c|c|c|c|c|c|}
\hline Concrete & $\begin{array}{l}\text { Water- } \\
\text { cement } \\
\text { ratio }\end{array}$ & $\begin{array}{l}\text { Water } \\
\left(\mathrm{kg} / \mathrm{m}^{3}\right)\end{array}$ & $\begin{array}{l}\text { Portland } \\
\text { cement } \\
\left(\mathrm{kg} / \mathrm{m}^{3}\right)\end{array}$ & $\begin{array}{l}\text { LASC } \\
\left(\mathrm{kg} / \mathrm{m}^{3}\right)\end{array}$ & $\begin{array}{l}\text { Sand } \\
\left(\mathrm{kg} / \mathrm{m}^{3}\right)\end{array}$ & $\begin{array}{l}\text { Rock } \\
\left(\mathrm{kg} / \mathrm{m}^{3}\right)\end{array}$ & $\begin{array}{l}\text { Fly ash } \\
\left(\mathrm{kg} / \mathrm{m}^{3}\right)\end{array}$ & $\begin{array}{l}\text { Mineral } \\
\text { powder } \\
\left(\mathrm{kg} / \mathrm{m}^{3}\right)\end{array}$ & $\begin{array}{l}\text { Super } \\
\text { plasticizer } \\
\left(\mathrm{kg} / \mathrm{m}^{3}\right)\end{array}$ & $\begin{array}{l}\text { Aluminum } \\
\text { Sulfate } \\
\left(\mathrm{kg} / \mathrm{m}^{3}\right)\end{array}$ & $\begin{array}{l}\text { Maximum } \\
\text { diameter of } \\
\text { the aggregate } \\
(\mathrm{mm})\end{array}$ \\
\hline $\mathrm{C} 60$ & 0.32 & 160 & 395 & - & 595 & 1105 & 55 & 50 & 10 & - & 25 \\
\hline FRHC & 0.37 & 176 & - & 475 & 630 & 1165 & - & & 7.125 & 6.05 & 15 \\
\hline
\end{tabular}

specimens, and its mixture is also shown in Table 3. The C60 concrete was commercial concrete obtained from the market, and the FRHC concrete was produced by $350 \mathrm{~L}$ self-falling concrete mixer in laboratory. The properties of each kind of concrete mixture are listed in Table 4.

There are two types of steel bars used in slabs specimens, which are HRB 335 with $16 \mathrm{~mm}$ and $12 \mathrm{~mm}$ in diameter. The steel bars were subjected to tensile test and the properties are listed in Table 5.

\subsection{Experimental program}

\subsubsection{Fabrication procedure}

The monolithic slab specimen and the precast slab specimens were cast by one timepouring with $\mathrm{C} 60$ concrete. After the precast specimens reaching the specific strength, all interfaces between precast slabs and joint connections were roughened by a bush hammer for exposing the aggregates and were cured for 28 days, then the joint connections between the precast slabs specimens were cast with FRHC. The demolding procedure was carried out 2 days after pouring concrete, and the specimens were coated and cured for 28 days as recommended by the specifications. The fabrication procedures are shown in Fig. 5.

\subsubsection{Reinforcement details}

Specimen M1 is a monolithic specimen without joint connection. There are two layers of rebars having the same reinforcing details in specimen M1. Usually, the traffic direction was defined as longitudinal direction and the transverse direction is perpendicular to the traffic direction. But in this experiment, the traffic direction is defined as transverse direction, while the longitudinal direction is perpendicular to the traffic direction. At the top layer of the reinforcement, 5 straight bars with a diameter of $16 \mathrm{~mm}$ along the longitudinal direction were arranged as longitudinal bars. They were $75 \mathrm{~mm}$ in spacing and 1450 $\mathrm{mm}$ in long. And 15 straight bars with diameter of $16 \mathrm{~mm}$ along the transverse direction were arranged as transverse bars. They were $100 \mathrm{~mm}$ in spacing and $450 \mathrm{~mm}$ in long. As for the vertical ties, there were 27 straight bars with a diameter of $12 \mathrm{~mm}$ arranged and their longitudinal spacing and transverse spacing were of 200 and $100 \mathrm{~mm}$ respectively. The drawing of the M 1 is shown in Fig. 3b.

For the joint specimens, the reinforcement details in the precast slabs were almost similar to M1. There are also two layers of rebars in the two precast parts. Five straight bars with a diameter of $16 \mathrm{~mm}$ along the longitudinal direction were arranged as longitudinal bars and they were $75 \mathrm{~mm}$ in spacing. And 5 straight bars with diameter of 12 $\mathrm{mm}$ along the transverse direction were arranged as transverse bars and they were 100 $\mathrm{mm}$ in spacing. As for the vertical ties, 9 straight bars with a diameter of $12 \mathrm{~mm}$ were 


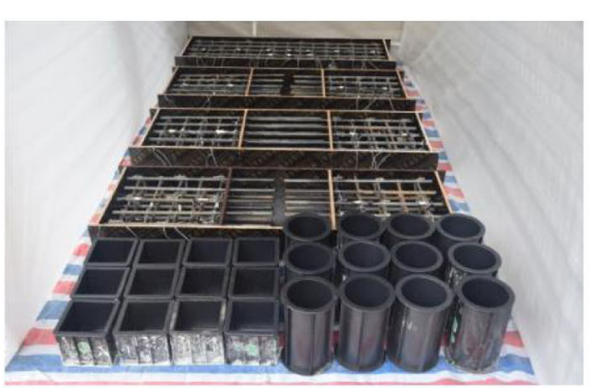

(a)

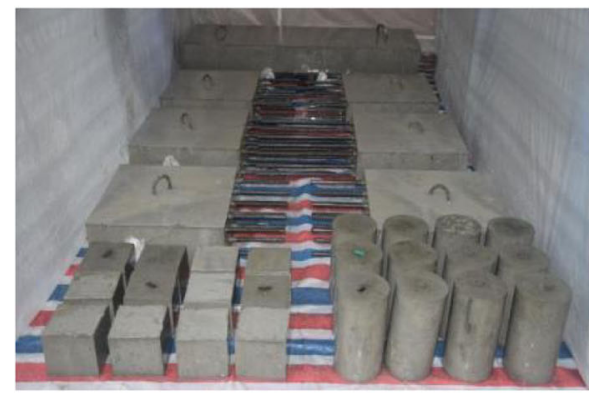

(c)

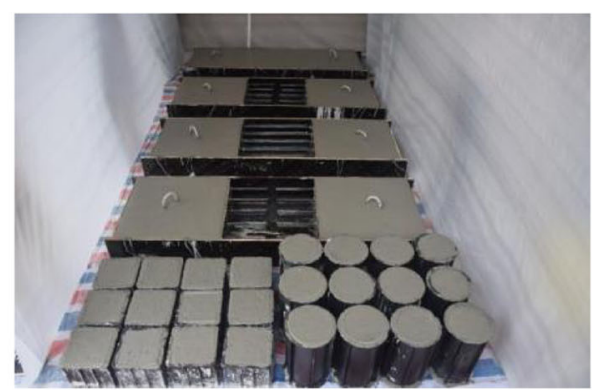

(b)

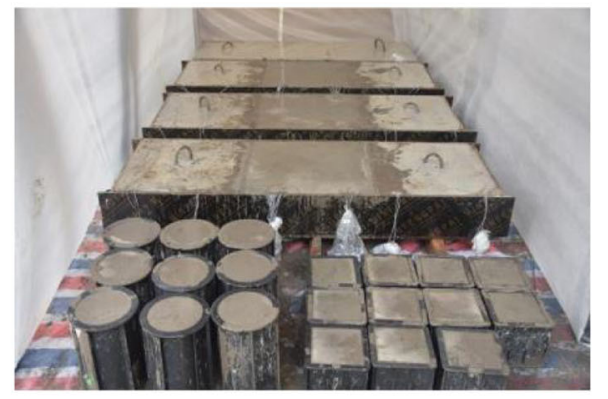

(d)

Fig. 4 Fabricating the specimens (a) preparation; (b) slabs fabrication; (c) demolding; (d) casting monolithic joint

arranged and their longitudinal spacing and transverse spacing are of 200 and $100 \mathrm{~mm}$ respectively.

For specimen JF1, 5 circumstantial bars were embedded with diameter of $16 \mathrm{~mm}$, located in the center of the joint zone along longitudinal direction spacing $75 \mathrm{~mm}$. The circumstantial bars were bent at their center of both sides down 180 degrees, with internal bending diameter of $120 \mathrm{~mm}$, and tied with the longitudinal bars protruding from the precast sections, with a lapping length of $360 \mathrm{~mm}$. For specimen JF2, the longitudinal bars extended from the precast slabs were tied together with lapping length of $480 \mathrm{~mm}$. In the joint zone of specimen JF 3, five bars having standard hooks at both ends with diameter of $16 \mathrm{~mm}$, transverse spacing of $75 \mathrm{~mm}$ were tied with longitudinal bars with lapping length of $400 \mathrm{~mm}$, which is shown in Fig. 3e. According to ACI 318-11, the standard hooks are 90-degree hook, which were designed as 90-degree bend plus $6 \mathrm{~d}$ ( $\mathrm{d}$ means the diameter of the bar) extension at free end of the bar, the diameter of bend was measured on the inside of the bar, other than for stirrups and ties, shall not be less than the values of six times of rebars diameter. The drawings of the hook is shown in Fig. 3f. In the joint connection, there were 8 lacer-bars, four of them were located in the top layer and the other were located in the bottom layer. Besides, 6 vertical bars were arranged in the joint zone, and the location and specific details were shown in Fig. 3c.

\subsubsection{Test set up and instrumentation}

The test specimen was placed in a simply supported condition with the span of $500 \mathrm{~mm}$. The loading was arranged for four-point bending condition. A manual hydraulic actuator 
Table 4 Summary of test results

\begin{tabular}{|c|c|c|c|c|c|c|c|c|c|c|c|}
\hline \multirow[t]{2}{*}{ Specimen } & \multicolumn{4}{|c|}{ C60 concrete } & \multicolumn{4}{|l|}{ LASC } & \multirow{2}{*}{$\begin{array}{l}V_{c r} \\
(\mathrm{kN})\end{array}$} & \multirow{2}{*}{$\begin{array}{l}V_{u} \\
(\mathrm{kN})\end{array}$} & \multirow{2}{*}{$\begin{array}{l}d_{v} \\
(\mathrm{~mm})\end{array}$} \\
\hline & $f_{c}(\mathrm{MPa})$ & $\begin{array}{l}f_{c}^{\prime} \\
(\mathrm{MPa})\end{array}$ & $f_{t}(\mathrm{MPa})$ & $\begin{array}{l}E\left(\times 10^{4}\right. \\
M P a)\end{array}$ & $\overline{f_{c}(\mathrm{MPa})}$ & $\begin{array}{l}f_{c}^{\prime} \\
(\mathrm{MPa})\end{array}$ & $f_{t}(\mathrm{MPa})$ & $\begin{array}{l}E\left(\times 10^{4}\right. \\
M P a)\end{array}$ & & & \\
\hline M1 & 64.61 & 63.07 & 5.78 & 3.387 & - & - & - & - & 55.4 & 252.3 & 14.35 \\
\hline$J F 1$ & 64.61 & 63.07 & 5.78 & 3.387 & 67.08 & 63.49 & 5.86 & 3.334 & 35.5 & 160.2 & 4.534 \\
\hline$J F 2$ & 64.61 & 63.07 & 5.78 & 3.387 & 67.08 & 63.49 & 5.86 & 3.334 & 50.8 & 248.2 & 8.838 \\
\hline JF3 & 64.61 & 63.07 & 5.78 & 3.387 & 67.08 & 63.49 & 5.86 & 3.334 & 34.2 & 177.6 & 3.348 \\
\hline
\end{tabular}

Notation: $f_{c}$ : cubic compressive strength; $f_{c}^{\prime}$ : cylinder compressive strength; $f_{t}$ : split cylinder cracking strength; $E$ : modulus of elasticity; $V_{c r}$ : cracking load; $V_{u}$ : ultimate load; $d_{v}$ : the maximum displacement of the loading point

having $50 \mathrm{t}$ capacity was fixed on a reaction frame. The reaction frame was anchored to the ground. The vertical load was controlled through load cells between the actuator and specimen. Deflections were measured with linear variable differential transformers (LVDTs) located at midspan, load points, and two supports, and were transferred through DH3816N numerical collector. Three strain gauges were implemented at the middle of the monolithic joint at three layers. The detailed layout is shown in Fig. 6. The specimen was tested with the increment $5 \mathrm{kN}$, the load was maintained for 3 minutes at each increment to mark cracks, measure width of cracks and take photos.

\subsection{Results and discussions}

\subsubsection{Failure mode}

All specimens experienced almost the same failure process. The initial cracks occurred at the central zone of the monolithic specimen M1, and at the interface between new and old concrete of the joint specimens. As the loads increased, several slightly cracks initiated between the top surface of loading point and the supports, and the existing cracks widened. With the propagation of the cracks along the longitudinal direction and transverse direction, the master cracks were formed. When the failure happened, it was observed that the compressive zone at the supports of M 1 was crushed, the master cracks at interfaces of JF 2 ran through the interface. It is worth mentioning that, JF 2's cracks development at the joint was slower than the other connection specimens. As for specimens JF 1 and JF 3, they almost shared the same failure mode with JF 2, while their cracks in the joint connection did not distribute as evenly as JF 2's did. The failure phenomenon of the slab specimens are shown in Fig. 7.

\subsubsection{Cracking loads and ultimate loads}

Table 4 lists cracking loads, ultimate loads and ratio $\rho$ (the ratio of cracking load to ultimate load) of each specimen. It was noticed that all the specimens have the almost

Table $\mathbf{5}$ Property of the steel

\begin{tabular}{llllll}
\hline $\begin{array}{l}\text { Diameter } \\
(\mathbf{m m})\end{array}$ & $\begin{array}{l}\text { Section area } \\
\left(\mathbf{m m}^{\mathbf{2}}\right)\end{array}$ & $\begin{array}{l}\text { Yield strength } \\
(\mathbf{M P a})\end{array}$ & $\begin{array}{l}\text { Ultimate strength } \\
(\mathbf{M P a})\end{array}$ & $\begin{array}{l}\text { Modulus of elasticity } \times \mathbf{1 0}^{\mathbf{3}} \\
(\mathbf{M P a})\end{array}$ \\
\hline b12 & 12 & 113.1 & 419.0 & 535.9 & 200 \\
b16 & 16 & 201.0 & 446.5 & 595.5 & 200 \\
\hline
\end{tabular}




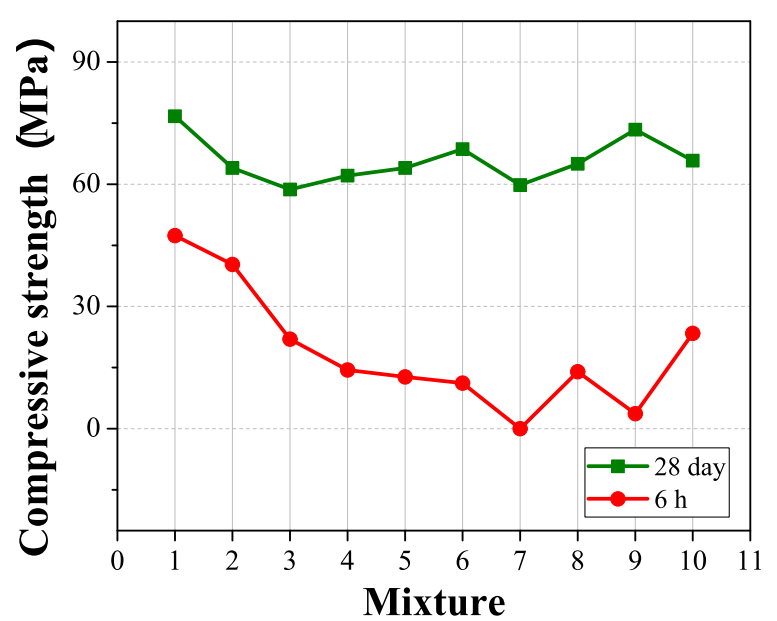

Fig. 5 The compressive strength of 6 hour and 28 day

the same ratio $\rho$, which almost equaled to $20 \%$, indicating the negligible contribution of splicing rebars details to the cracking behavior. The specimen M 1 and JF 2 have the similar ultimate load of $250 \mathrm{kN}$, which is larger 55\% than specimen JF 1 and JF 3's, indicating that the rebars splicing details has significant influence on the flexural capacity of the specimens. Considering the test results, the splicing details of JF 2 behaved better and would be recommended.

\subsubsection{Load-deflection response}

The deflection of two loading points were obtained and compared, which is shown in Fig. 8. The loads of different deflections, the ultimate load and the ultimate deflection for each specimen are summarized in Table 6.

It can be seen from Fig. 8 that the M1 and JF2 curves can be divided in four stages which are elastic stage, elastic-plastic stage, yielding stage and failure stage. In elastic stage, the specimens did not crack, the curves developed linearly with the stress increment until the first cracks occurred. The deflection developed slower and did not experience the stiffness loss. In elastic-plastic stage, the concrete at the tensile zone began to crack, the structure began to defect and specimen experienced the stiffness loss. With the load increasing, the cracks developed longer and wider, the curves exhibited nonlinear characteristic and the tensile stress at the tensile was carried only by rebars. In yielding stage, the curves reached plateau, the rebars were yielded, the deflection increased very fast, which means the specimen experienced great stiffness loss and was about to fail. In failure stage, the deflection increased very quickly while the load decreased very fast. The specimen was damaged, local concrete was compressed to crush and load capacity decreased.

From Fig. 8 it can be seen that specimens M 1 and JF 2 exhibited the almost same procedure to damage. But the curves of specimen JF1 and JF 3 were not perfectly matched with the four stages procedure. JF 1and JF 3's curves do not have the plateau segment, meaning that JF1 and JF 3 did not experience the yielding stage, the concrete 


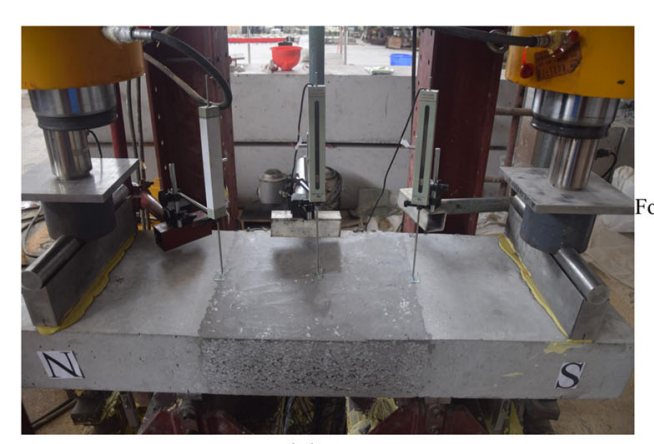

(a)

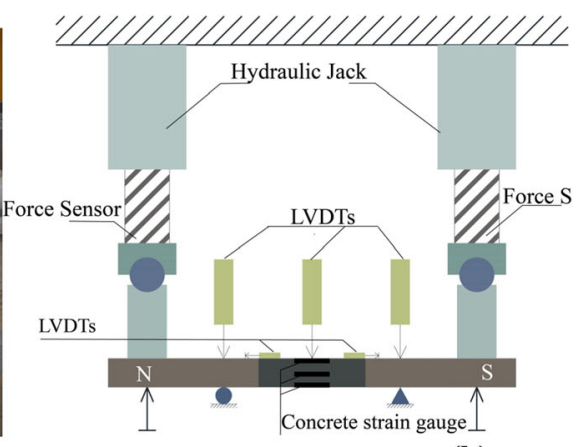

(b)

Fig. 6 The experimental setup and instrument (a) photo of experimental setup and instrument; and (b) sketch of experimental setup and instrument

at the connection cracked severely prior to the transverse bars yielding, the anchorage between rebars and concrete was invalid, resulted in the failure of the specimen. From the Fig. 8, in elastic stage, the slope of specimen M 1's curve is the lowest, indicating that the specimens with joints have the higher flexural stiffness. It can be concluded that, under four-point bending condition, specimen JF 2 behaved more like monolithic specimen than other joint specimens.

\subsubsection{Deformation and strain characteristics}

The deflections distributed along the slab at different vertical loads are illustrated in Fig. 9. The deflection profiles of joint specimens are not as uniform and symmetric as those of monolithic slab. As load increased, the vertical displacement of each point also increased gradually. Compared to monolithic slab M 1, the stiffness of the joint specimens were weaker. The strain distributed in midspan cross sections of specimens subjected to different load are depicted in Fig. 10. As the loads of specimens M 1, JF 1 and JF 2 were less than $60 \mathrm{kN}$, the specimen JF 3 was less than $50 \mathrm{kN}$, the relationship between strain and height of concrete was linear. The behavior of the specimens followed the plane-section assumption, and the strain value of each point corresponding to each specimen under the same loading condition was equivalent. The relationship of strain and heights of concrete became nonlinear as the load increased over $60 \mathrm{kN}$. At the same time, the number of cracks developed, the width of the cracks expanded.

\section{Practical and application of FRHC with LASC}

Based on the preliminary test results in the laboratory and the practical construction environment of Guang-Hui Expressway, the FRHC with LASC was adopted to fill the longitudinal joint connections between existing decks and newly-built one in west extension Construction of Guanghui Expressway. The field application was shown in Fig. 11. Through measurement, the maximum deflection of the newly built bridge under the influence of traffic loads was $0.432 \mathrm{~mm}$. The field construction was conducted at night during its minimal traffic flow, while the existing bridge remained open to traffic normally. The slump of the applying concrete mixture was $100 \mathrm{~mm}$, showing 


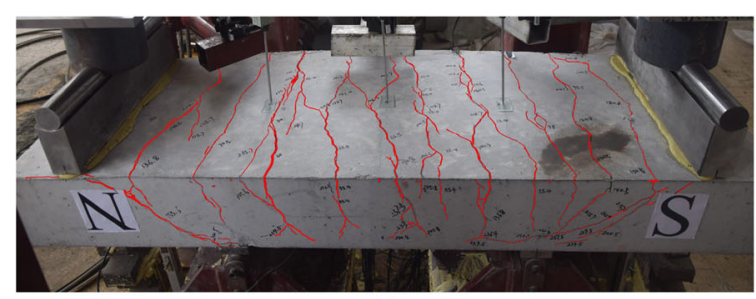

(a)

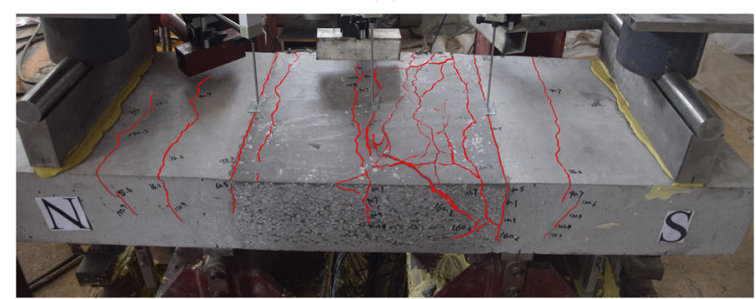

(b)

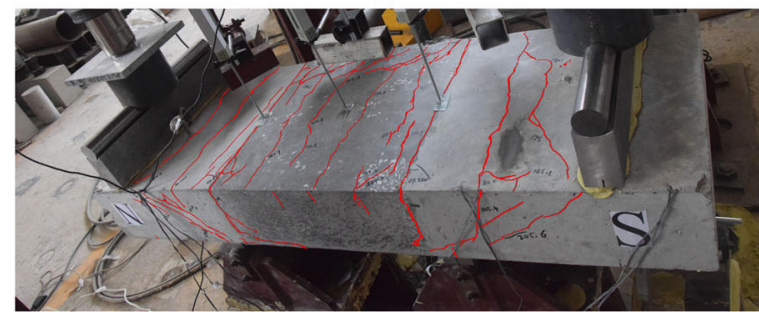

(c)

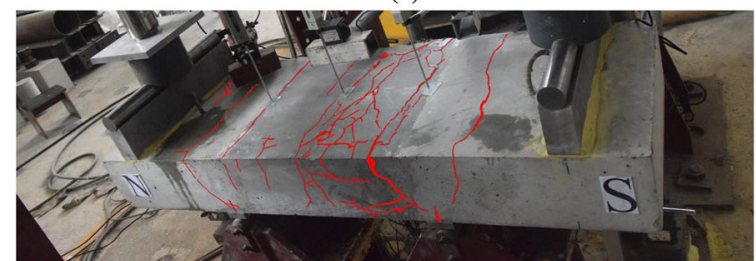

(d)

Fig. 7 Crack distribution. a M1; b JF 1; c JF2; d Jf 3

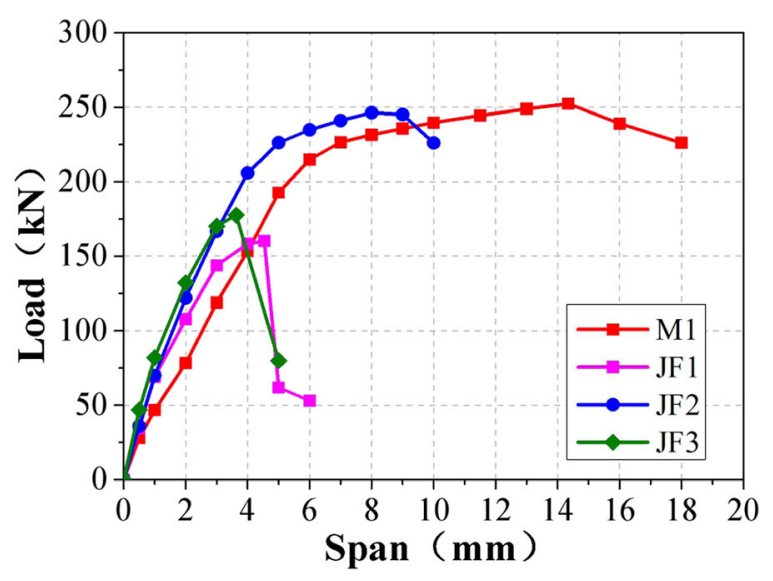

Fig. 8 Comparison of load-deflection curves 
Table 6 Load and load ratio for the deflection $1 \mathrm{~mm}, 2 \mathrm{~mm}$ and $3 \mathrm{~mm}$

\begin{tabular}{llllll}
\hline Specimen & Load $(\mathbf{k N})$ & & & $\boldsymbol{P}_{\boldsymbol{u}}$ & $\boldsymbol{f}_{\boldsymbol{u}}$ \\
\cline { 2 - 4 } & $\mathbf{L - 1}$ & $\mathbf{L - 2}$ & $\mathbf{L - 3}$ & & \\
\hline M1 & 46.7 & 78.2 & 118.9 & 252.3 & 14.350 \\
JF1 & 69.1 & 107.8 & 143.7 & 160.2 & 4.535 \\
JF2 & 69.9 & 122.0 & 166.7 & 246.3 & 8.000 \\
JF3 & 82.0 & 132.1 & 170.2 & 177.6 & 3.628 \\
\hline
\end{tabular}

Notation: L-1, L-2 and L-3 represent the load responding to the deflection of $1 \mathrm{~mm} 2 \mathrm{~mm}$ and $3 \mathrm{~mm}$ respectively; $P_{u}$ represents the ultimate load; $f_{u}$ represent the ultimate deflection

a good working performance during the construction. Its compressive strength reached 15.9 MPa at $6 \mathrm{~h}$, and $44.8 \mathrm{MPa}$ at $12 \mathrm{~h}$ that met the bridge standard. After an overnight curing, the longitudinal joint was able to come into service with good mechanical performance, and no cracks appeared.

\section{Conclusion}

A new FRHC with LASC was developed for the construction of longitudinal joint between the existing bridge and the newly built one, to meet the needs of rapid construction without traffic interruption. By adding aluminum sulfate, Polycarboxylic SP, and steel fibers, FRHC with LASC could avoid the influence of traffic vibrations owing to its characteristic of fast hardening, retarding and high early strength. To investigate the flexural behavior of the joint filled with newly developed concrete, four slab

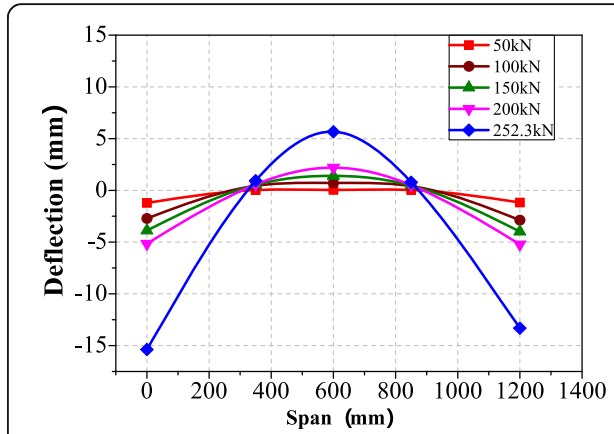

(a)

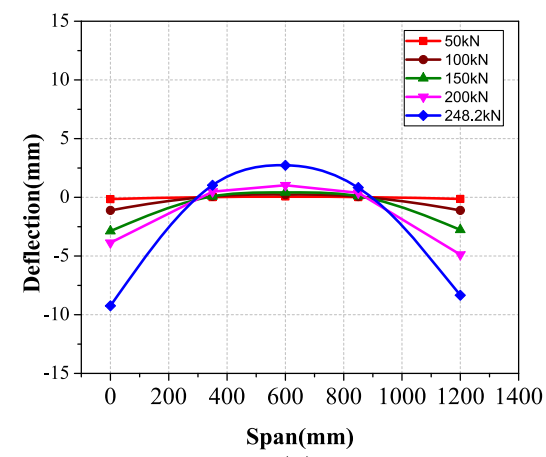

(c)

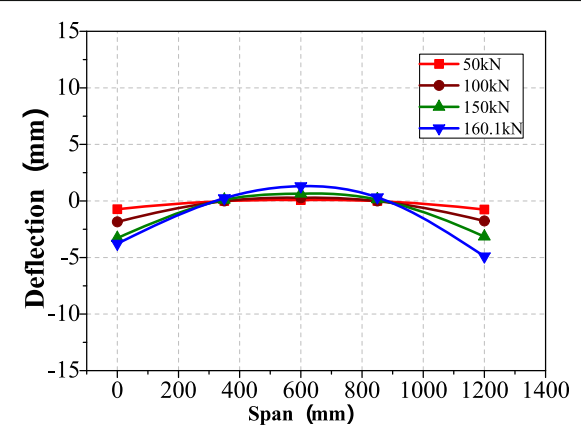

(b)

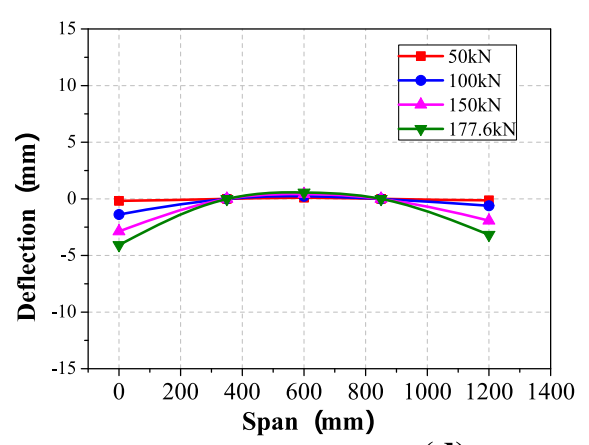

(d)

Fig. 9 Deflection along typical composite concrete beams under load. a M1; b JF 1; c JF 2; d JF 3 


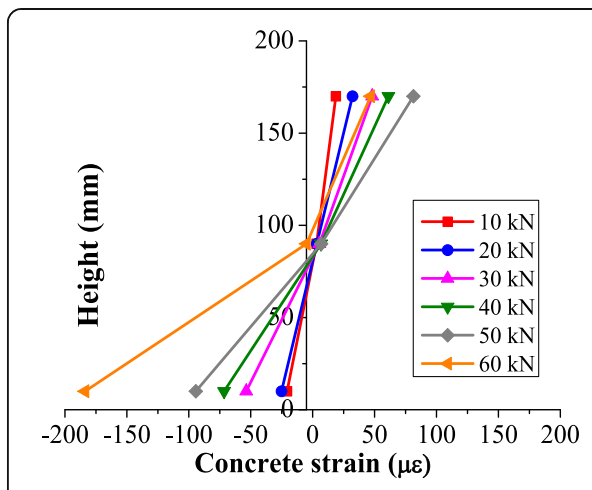

(a)

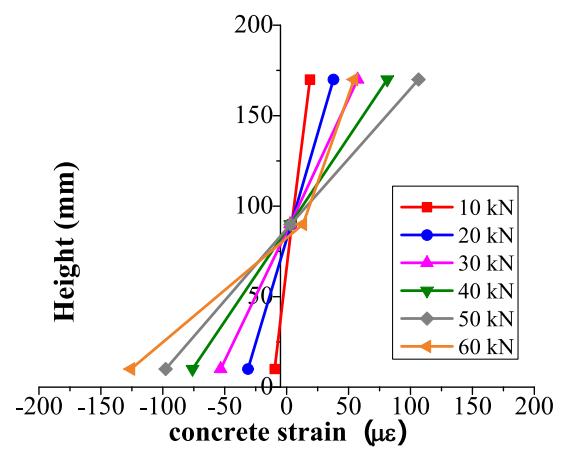

(c)

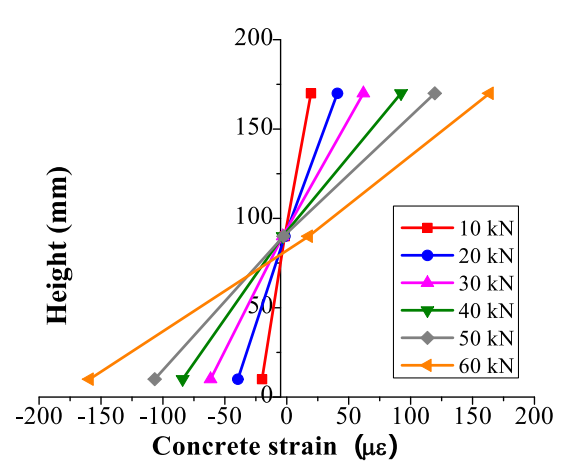

(b)

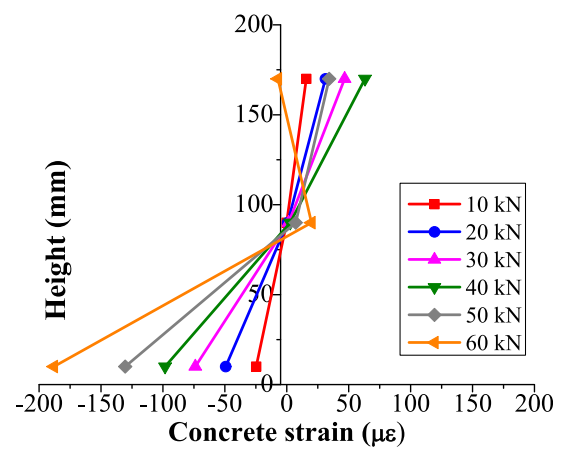

(d)

Fig. 10 Strain Distribution in midspan cross sections of specimens. a M 1; b JF 1; c JF 2; d Jf 3

specimens were cast and tested to study the flexural behavior. The main conclusions can be drawn as following.

1. In this study, $0.6 \%$ of borax was added as retarder to prolong the setting time of the concrete. However, the concrete with $0.6 \%$ of borax could set at $12 \mathrm{~h}$ which failed to meet the construction requirement. To study the retarding behavior of borax, more researches should be conducted.

2. The concrete with a higher content of aluminum sulfate performed a higher compressive strength at $6 \mathrm{~h}$, but was exceeded by that with lower content after 1 day. Higher content of aluminum sulfate would cause a rapid hydration and results in high-early strength, but produce overlarge ettringite crystal which were unevenly distributed. Because of the unevenly distribution of ettringite crystal in the cement paste, the strength enhancement was inhibited.

3. Compared with the concrete with naphthalene SP, the concrete with polycarboxylic SP showed a dramatically increment of compressive strength during 6-12 h. Concrete with steel fibers reached an increment of $38.1 \%$ on splitting tensile strength, resulting from the bond strength between fibers and the matrix.

4. For all joint specimens, The cracking load of joint specimens are about $20 \%$ of the ultimate load, which is almost similar with the monolithic specimen, and the rebars splicing details has little influence on it. The first crack was always occurred at the interface between the joint connection and the precast slabs. 


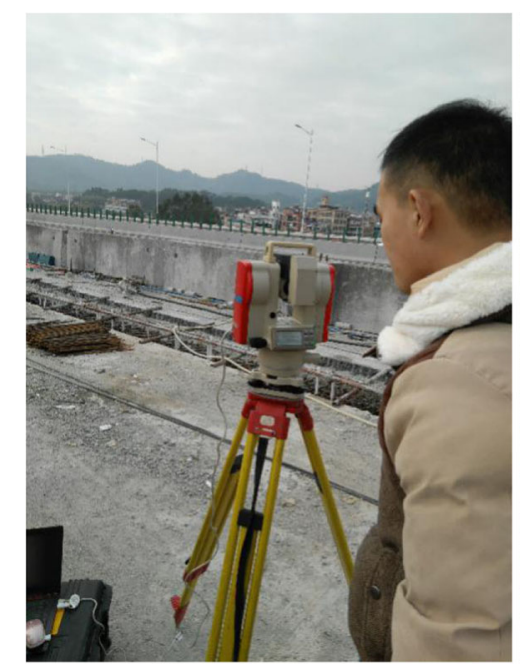

(a)

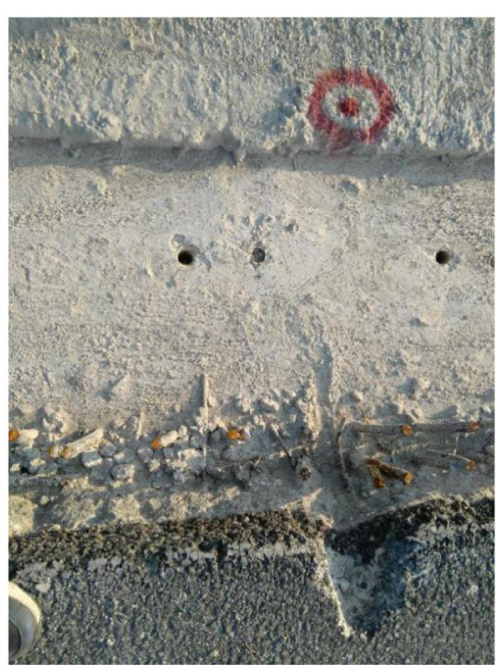

(b)

Fig. 11 Field application of FRHC. a Building the connection, b the connection

5. The load-deflection curves of M 1 and JF 2 specimens can be divided into four stages, i.e., elastic stage, elastic-plastic stage, yielding stage and failure stage. The flexural stiffness of the joint specimens is dependent on the splicing details. In this research, it can be drawn that the JF 2's splicing details behaved better, which behaved almost similar to monolithic specimen. Compared with JF 1 and JF 3, the flexural behavior of specimen JF 2 are more consistent with the monolithic slab specimen $M 1$, exhibiting higher capacity and ductility, therefore, the rebars splicing details of specimen JF 2 is applicable and workable.

6. Casting the joint connection with proper rebars detail and newly developed FRHC, the joint slab exhibits similar mechanical properties to monolithic slab. Considering the performance of FRHC in Guanghui expressway widening construction, the newly developed FRHC has the potentiality to apply in practical engineering.

\section{Abbreviations}

FRHC: Fast-hardening retarding high-early-strength concrete; LASC: Low-alkalinity sulphoaluminate cement; OPC: The ordinary Portland concrete; SPS: Superplasticizers; W/B: Water-binder ratio; FHSC: Fast-hardening sulphoaluminate cement

\section{Acknowledgements}

This study was supported by National Nature Science Foundation of China (Grant No.51778150), Nature Science Foundation of Guangdong Province in China (2016A03031699) and Science and Technology Planning Project of Guangzhou City in China (Grant No.20180410422). The authors gratefully acknowledgment.

\section{Authors' contributions}

Data curation, Zhijun Sha; Formal analysis, Zhijun Sha, Jiahui Feng and Tianlong Wang; Funding acquisition, Xiang Long and Haibo Jiang; Investigation, Xiang Long, Haibo Jiang and Tianlong Wang; Methodology, Haibo Jiang; Writingoriginal draft, Zhijun Sha and Jiahui Feng; Writing-review \& editing, Zhijun Sha and Haibo Jiang. The authors read and approved the final manuscript.

\section{Funding}

The research presented was sponsored by National Natural Science Foundation of China [51778150], Natural Science Foundation of Guangdong Province in China [2016A030313699] and Science and Technology Planning Project of Guangzhou city in China [201804010422].

\section{Availability of data and materials}

The datasets used and analyzed during the current study are available from the corresponding author on reasonable request. 


\section{Competing interests}

The authors declare no conflict of interest.

\section{Author details}

${ }^{1}$ School of Civil and Transportation Engineering, Guangdong University of Technology, Guangzhou 510006, China.

${ }^{2}$ Yuexiu Transport Infrastructure Co. LTD, HongKong 999077, China. ${ }^{3}$ Dongguan Road and Bridge Investment

Construction Co. LTD, Dongguan 523416, China.

Received: 9 November 2020 Accepted: 10 December 2020

Published online: 23 December 2020

\section{References}

Aggoun S, Cheikh-Zouaoui M, Chikh N, Duval R (2008) Effect of some admixtures on the setting time and strength evolution of cement pastes at early ages. Constr Build Mater 22(2):106-110

Alhosani Kl, Yousri KM, Aishamsi AM (1997) Hydrophobic materials, superplasticizer and microsilica effects on setting of cement pastes at various temperatures. Mag Concrete Res 49(179):111-115

Alshamsi AM, Sabouni AR, Bushlaibi AH (1993) Influence of set-retarding superplasticisers and microsilica on setting times of pastes at various temperatures. Cement Concrete Res 23(3):592-598

Batis STCK (2002) An analysis of the properties of Portland limestone cements and concrete. Cem Concr Compos 24(3-4): 371-8. https://doi.org/10.1016/S0958-9465(01)00089-0

Berger RH (1983) 62nd Annual Meeting of the Transportation Research Board. United States: Washington District of Columbia 52-9.http://onlinepubs. trb.org/Onlinepubs/trr/1983/903/903-007.pdf

Celik T (1995) Setting Times of Fly Ash and Slag-Cement Concretes as Affected by Curing Temperature. Cement Concrete Aggregates 17(1):11-17. https://doi.org/10.1520/CCA10331J

Champenois JB, Cau-Dit-Coumes C, Poulesquen A (2013) Conditioning Highly Concentrated Borate Solutions with Calcium Sulfoaluminate Cement. Cement-Based Materials for Nuclear Waste Storage. Springer, New York, pp 203-213

Champenois JB, Dhoury M, Céline CDC, Mercier C, Revel B, Bescop PL et al (2015) Influence of sodium borate on the early age hydration of calcium sulfoaluminate cement. Cement Concrete Res. 70:83-93

Chen XT, Davy CA, Skoczylas F, Shao JF (2009) Effect of heat-treatment and hydrostatic loading upon the poro-elastic properties of a mortar. Cement Concrete Res 39(3):195-205

Collepardi M, Valente M (2006) Recent developments in superplasticizers. In: 8th CANMET/ACI International Conference on Superplasticizers and Other Chemical Admixtures in Concrete, pp 1-14

Editor VMM (1995) Advances in concrete technology. Economical Constr Concrete Dams, Gordon and Breach. http://www1. lib.kanazawa-u.ac.jp/en/recordID/catalog.bib/BA33034293

Gartner E (2004) Industrially interesting approaches to "low-CO2" cements. Cement Concrete Res 34(9):1489-1498

Gastaldini ALG, Isaia GC, Saciloto AP, Missau F, Hoppe TF (2010) Influence of curing time on the chloride penetration resistance of concrete containing rice husk ash: a technical and economical feasibility study. Cement Concrete Comp 32(10):783-793

Glasser FP, Zhang L (2001) High-performance cement matrices based on calcium Sulfoaluminate-Belite compositions. Cement Concrete Res 31(12):1881-1886

Guo S, Zhang Y, Wang K, Bu Y, Wang C, Ma C et al (2019) Delaying the hydration of Portland cement by sodium silicate: Setting time and retarding mechanism. Constr Build Mater 205(APR.30):543-548

Guo T, Xie Y, Weng X (2018) Evaluation of the bond strength of a novel concrete for rapid patch repair of pavements. Constr Build Mater 186(OCT.20):790-800

Hargis CW, Telesca A, Monteiro PJM (2014) Calcium sulfoaluminate (Ye'elimite) hydration in the presence of gypsum, calcite, and vaterite. Cement Concrete Res 65:15-20

Juenger MC, Winnefeld F, Provis JL, Ideker JH (2011) Advances in alternative cementitious binders. Cement Concrete Res 41 (Issue 12):1232-1243

Kenai S, Soboyejo W, Soboyejo A (2004) Some Engineering Properties of Limestone Concrete. Mater Manuf Process 5(5):949961

Khedr SA, Abou Zeid MN (1994) Characteristics of silica-fume concrete. J Mater Civil Eng 6(3):357-375

Kwon JB, Kim D, Rhee KS et al (2018) Spray injection patching for pothole repair using 100 percent reclaimed asphalt pavement. Constr Build Mater 166:445-51. https://doi.org/10.1016/j.conbuildmat.2018.01.145

Lewis S (2009) Experimental investigation of precast bridge deck joints with u-bar and headed bar joint details. University of Tennessee, Knoxville

Li L, Ma ZJ, Oesterle RG (2010) Improved longitudinal joint details in decked bulb Tees for accelerated bridge construction: fatigue evaluation. J Bridg Eng 15(5):511-522

Liu Y, Jia M, Song C (2020) Enhancing ultra-early strength of sulphoaluminate cement-based materials by incorporating graphene oxide. Nanotechnol Rev 9(1):17-27

Ma B, Zhi Z, Tan H et al (2017) Effect of borax on rheology of calcium sulphoaluminate cement paste in the presence of polycarboxylate superplasticizer. Constr Build Mater 139:77-85. https://doi.org/10.1016/j.conbuildmat.2017.02.005

Ma J, Yu Z, Ni C, Shi H, Shen X (2019) Effects of limestone powder on the hydration and microstructure development of calcium sulphoaluminate cement under long-term curing. Constr Build Mater 199(FEB.28):688-695

Martin LHJ, Winnefeld F, Müller CJ, Lothenbach B (2015) Contribution of limestone to the hydration of calcium sulfoaluminate cement. Cement Concrete Comp 62:S577187556

Matschei T, Lothenbach B, Glasser FP (2007) The role of calcium carbonate in cement hydration. Cement Concrete Res 37(4): $551-558$

Naik TR, Ramme BW (1990) Effects of high-lime fly ash content on water demand, time of set, and compressive strength of concrete. ACI Mater J 87(6):619-626

Naik TR, Singh SS (1997) Influence of fly ash on setting and hardening characteristics of concrete systems. ACI Mater J 94(5): $355-360$ 
Popescu CD, Muntean M, Sharp JH (2003) Industrial trial production of low energy belite cement. Cement Concrete Comp 25(7):689-693

Ryu HK, Kim YJ, Chang SP (2007) Experimental study on static and fatigue strength of loop joints. Eng Struct 29(2):145-162 Sakai E, Ishida A, Ohta A (2006) New trend in the development of concrete admixtures in Japan. J Adv Concr Technol 4(2): $211-223$

Sakellariou STTK (2003) The permeability of Portland limestone cement concrete. Cement Concrete Res 33(9):1465-71. https://doi.org/10.1016/50008-8846(03)00092-9

Schneider M, Romer M, Tschudin M, Bolio H (2011) Sustainable Cement Production - Present and Future. Cement Concrete Res 41(7):642-650

Standard for Test Method of Concrete Physical and Mechanical Properties(GB/T 50081-2019). Ministry of Housing and UrbanRural Development of People's Republic of China. 2019

Sun Q, Li J, Wang J (2011) Effect of borate concentration on solidification of radioactive wastes by different cements. Nucl Eng Des 241(10):4341-4345

Theodossis CGG (2000) Properties and behavior of limestone cement concrete and mortar. CEMENT Concrete Res 30(10): 1679-83.https://doi.org/10.1016/S0008-8846(00)00372-0

Wang S, Liu B, Zhao P, Lu L, Cheng X (2018) Effect of early-strength-enhancing agents on setting time and early mechanical strength of belite-barium calcium sulfoaluminate cement. J Therm Anal Calorim 131(3):2337-43. https://doi.org/10.1007/ s10973-017-6837-8

Wedding PA, Pistilli MF, R W (1984) The Uniformity and Influence of Silica Fume from a U.S. Source on the Properties of Portland Cement Concrete. Cement Concrete Aggregates 6(2):120-124. https://doi.org/10.1520/CCA10364J

Xu LL, Wang PM, Wu GM (2014) Effect of calcium sulfate on the formation of Ettringite in calcium aluminate and Sulfoaluminate blended systems. Key Eng Mater 599:23-28

Ye ZM, Chen W, Cheng X (2010) Impermeability of Sulphoaluminate Cement Mortar Modified by Redispersible Polymer Powders. Adv Mater Res 168-170:1886-1890

Zajac M, Skocek J, Bullerjahn F, Ben HM (2016) Effect of retarders on the early hydration of calcium-sulpho-aluminate (CSA) type cements. Cement Concrete Res 84:62-75

Zhang J, Gao X, Su Y (2019) Influence of poker vibration on aggregate settlement in fresh concrete with variable rheological properties. J Mater Civil Eng 31(7):4019121-4019128

\section{Publisher's Note}

Springer Nature remains neutral with regard to jurisdictional claims in published maps and institutional affiliations.

\section{Submit your manuscript to a SpringerOpen ${ }^{\circ}$ journal and benefit from:}

- Convenient online submission

- Rigorous peer review

- Open access: articles freely available online

- High visibility within the field

- Retaining the copyright to your article

Submit your next manuscript at $\mathbf{s p r i n g e r o p e n . c o m ~}$ 